\title{
On the robustness of minimum wage effects: geographically-disparate trends and job growth equations
}

\author{
John T. Addison 1,2,3, McKinley L. Blackburn ${ }^{1}$ and Chad D. Cotti ${ }^{4^{*}}$
}

\footnotetext{
* Correspondence: cottic@uwosh. edu

${ }^{4}$ University of Wisconsin-Oshkosh, Oshkosh, WI, USA

Full list of author information is available at the end of the article
}

\begin{abstract}
Recent attempts to incorporate spatial heterogeneity in minimum-wage employment models have been targeted for using overly simplistic trend controls and for neglecting the potential impact of wage minima on employment growth. This paper investigates whether such considerations call into question findings of statistically insignificant employment effects reported in the literature for an archetypal low-wage sector in the United States: restaurants and bars. Understanding this relationship goes to the heart of the policy debate surrounding minimum wages and, hence, is critical to investigate carefully. Our results conclude that a focus on employment levels is appropriate for this sector and, further, that the deployment of nonlinear trend controls does not dislodge prior research which finds weak support for the existence of adverse minimum-wage employment effects on employment.

JEL Classification: J23, J38

Keywords: Minimum wages, Employment, Employment change, Spatial controls
\end{abstract}

\section{Introduction}

In a critique of recent contributions to the literature on minimum wages, Neumark et al. (2014) have questioned the usefulness of common approaches to controlling for spatial heterogeneity in employment equations. In this project we attempt to conduct a fair arbitration regarding a contentious current dispute in the minimum wage literature regarding measurement and specification, with a focus on evaluating current empirical issues that may question the sensitivity of results from our earlier work on the topic (Addison et al. [hereafter $\mathrm{ABC}$ ] (2012)). In the process, we also address an alternative critique having a basis in the notion that minimum wage effects are more easily detected in employment growth than in employment levels, such that conventional controls for spatial heterogeneity may attenuate estimates of how the minimum wage affects the level of employment (Meer and West 2013). The wider backdrop to the present analysis is a recent meta-analysis by Belman and Wolfson (2014) of 23 modern minimum-wage studies, which controlled for study differences and concluded that minimum wages have no economically or statistically meaningful disemployment effects. ${ }^{1}$

Using a large sample of county-level employment data, $\mathrm{ABC}$ estimated the effect of minimum wages on employment in the restaurant-and-bar sector, 1990-2005. In 
addition to time and county fixed effects, the authors' model included a county-specific effect allowed to follow a linear trend over time (along with county-level controls) in a framework that permitted the investigators to assess the consistency of the estimates with a competitive-model explanation of employment and earnings determination.

In general, $\mathrm{ABC}$ concluded that minimum wages did not reduce employment in a sector that contains the highest percentage of workers at or below the relevant minimum wage in the United States and in which a little over 40 percent of workers worked for the minimum wage plus two dollars or less. The authors argued that their estimates could be considered largely consistent with a competitive model in which the elasticity of demand for labor was very small. In the present paper, we seek to evaluate the robustness of the results presented in $\mathrm{ABC}$ allowing for more flexible time trends, updating the sample period, and modeling employment changes as well as employment levels. The goal of the exercise is fundamentally to determine what can be learned from the recent debate surrounding the sensitivity of past results in light of new concerns surrounding the importance of alternative empirical approaches, much of which is to be viewed as constructive and productive of research progress. Overall, we view our empirical evidence as still consistent with minimum wage employment effects that are quite small or nonexistent.

\section{Two basic approaches, then and now}

\subsection{General statement}

As is well known, research on minimum wages has gone through several stages. But we will begin with the new minimum wage research of the early 1990s. This earlier phase of modern research focused on state data because of the advantages of using simultaneous panels rather than an aggregate time series. One branch exploited geographical variation in the setting of minimum wages in an industry case study approach, while the other used a standard state-panel analysis in which state effects were held constant.

Both approaches sought valid counterfactual control groups for what would have transpired absent increases in the minimum wage, and each reported generally divergent findings. (For a detailed review of this literature, see Neumark and Wascher 2007; 2008.) The case studies pointed to a lack of job loss-even gain$\mathrm{s}$-and the two-way state-panel approach suggested the opposite for long panels of data (with minimum wage elasticities in the range-0.1 to-0.3). Case studies of a particular change in the minimum wage in a particular industry typically used only a short time horizon (raising obvious concerns about missing lags in disemployment effects), and in covering individual cases raised problems of inference and external validity. For their part, the state-panel studies did not allow for heterogeneous trends in states that increased minimum wages; for example, states experiencing greater increases in minimum wages might have systematically different labor market characteristics unrelated to their minimum wage policies. Also, the state-panel studies largely failed to recognize the potential importance of within-state error correlation in constructing standard errors.

Enter the "new" new minimum wage research. This has taken two forms. One form has continued to use national panels that now incorporate geographic-specific trend 
variables as a means of controlling for heterogeneity in the underlying long-term growth prospects of low-wage employment (as well as other trends in teen employment). An example is the use of state or, as is the case for $A B C$, county linear trends. Another variant allows time effects to vary by Census division. Thus, the inclusion of division-specific time effects controls for spatial heterogeneity in differential employment patterns such as region-specific shocks (see Allegretto et al. 2011). Such division-specific controls either substitute for or supplement geographic-specific linear trends.

The second innovation has been to extend the case study approach using larger panels. For example, this approach has used a research design based on cross-border pairs in a specification that (initially) included county-pair/period interactions so as to control for shocks common to both counties. Thus, the effect of minimum wages was identified from differences in employment and minimum wages across paired counties on either side of a state border (see Dube et al. 2010).

These two approaches were (mostly) to yield results at odds with the standard state panel exercises, providing little or no evidence of job loss in sectors or for groups most likely to be impacted by minimum wage increases. Thus, Allegretto et al. (2011), using Current Population Survey (CPS) data on teens between 1990 and 2009, obtained minimum wage effects consistent with the standard state panel model before sweeping out the variation across Census divisions and allowing for state-specific trends, only to report essentially zero employment (and indeed hours) elasticities after their inclusion. ${ }^{2}$ Other interesting results from their study were (a) an absence of anticipation effects with the inclusion of the two spatial controls and (b) a seeming lack of differing employment effects over the business cycle.

For their part, $\mathrm{ABC}$ used Quarterly Census of Employment and Wages (QCEW) administrative data for 1990-2005 for the restaurant-and-bar sector and obtained a very similar pattern of results: negative and statistically significant coefficient estimates for the log minimum wage in employment regressions containing fixed county and time fixed effects that declined sharply in absolute magnitude and became statistically insignificant with the incorporation of county-specific trends. As they noted (2012: 424), “... employment in the restaurant-and-bar sector tends to exhibit a downward trend in states that have increased their minimum wages relative to states that have not, biasing the fixed effect ... estimates ... towards finding a negative employment effect of minimum wages." ${ }^{3}$ Returning to the point made earlier about reliance on individual sectors, we note that the same authors had earlier estimated minimum wage impacts in other low-wage sectors in the retail sector using data at the county level, again reporting little evidence of disemployment effects (Addison et al. 2009).

Results for the border-county approach were presented in the study by Dube et al. (2010) Using the QCEW, the authors consider all adjacent counties straddling state borders for which data are available between 1990 and 2006. Of these 504 counties, some 337 in 288 pairs recorded some difference in minimum wages. As noted earlier, the impact of minimum wages is obtained from differences in employment changes in these paired counties using unique dummy variables for each pair interacted with time period. No evidence of employment losses-up to four years after a minimum wage increase-is reported for the two sectors (restaurants and retail) examined in the study. 


\subsection{Empirical specifications}

All of these models entail alternative approaches to handling trends in the error term that may be correlated with the minimum wage. Models specified at a county level that allow for spatial heterogeneity in the determination of an outcome variable $(\mathrm{E})$ can be written as:

$$
\log \left(E_{i s t}\right)=\beta_{1} \log \left(M W_{s t}\right)+\beta_{2} X_{i s t}+\lambda_{i s}(t)+\varepsilon_{i s t},
$$

for the observation from county $i$ in state $s$ in period $t$. Here, MW represents the prevailing minimum-wage, and $\mathrm{X}$ is a vector of other independent variables. In this general model, $\lambda_{i s}(t)$ reflects the unrestricted evolution of the county-specific effect over time-unidentified without some additional restrictions. The standard panel-data approach assumes:

$$
\lambda_{i s}(t)=\delta_{i}+\phi_{t}
$$

so that county-specific effects are assumed to change by the same amount (that is, follow the same trend) over time. The inclusion of state-specific trends generalizes this assumption to:

$$
\lambda_{i s}(t)=\delta_{i}+\phi_{t}+\gamma_{i} t
$$

allowing each county to follow its own employment trend over time, with the restriction that trend be linear.

The division-specific effects model of Allegretto et al. (2011) would assume:

$$
\lambda_{i s}(t)=\delta_{i}+\phi_{t}+\psi_{d t},
$$

where $\psi$ is an effect common to all counties in all states in division $d .^{5}$ This relaxes the linear assumption of equation (2)-these trends can evolve quite non-parametrically over time-but with the unattractive assumption that the evolution of the trend is common to a large geographic area (a Census division).

The border-county approach instead assumes:

$$
\lambda_{i s}(t)=\delta_{i}+\phi_{t}+\vartheta_{p t}
$$

where $\delta$ and $\phi$ are location and time fixed effects, respectively, and $\vartheta$ is a "pair effect" (specific to period $\mathrm{t}$ ) shared by a pair of counties in different states but with a border in common. (This entails restricting the sample to counties on a border with another state.) Compared with (3), this would seem to make the geographic area sharing a common trend more focused (the two counties in a border pair). However, in practice the application of the model is not quite so clean. Suppose county $i$ in state $s$ shares a border with county $j$ in state $q$. In any given period, they are assumed to share the effect $\vartheta_{p t}$. But any given border county is likely to share a border with more than one other county in the adjacent state. If county $i$ in state $s$ also borders county $j+1$ in state $q$, then logically that county should also have the same effect $\vartheta_{p t}$ : if it was the appropriate determinant of $E_{i s t}$ in the first border match, it should also be the determinant of $E_{i s t}$ in the second border match. Given the non-synchronization of county lines across state borders, this reasoning would lead to an implicit restriction that all counties along the border for states $s$ and $q$ have the same border-specific effect. Indeed, for some 
state-border matches this common effect would also extend to the border with another state (as a "corner county" generally borders more than one state).

In practice, Dube et al. (2012) do not impose this restriction (of identical pair effects across a given border). Rather, a separate $\vartheta_{p t}$ is estimated for each border-county match. ${ }^{6}$ At one level, this could be interpreted as an inefficient method of estimating the more logically-consistent model discussed in the previous paragraph. Alternatively, if the values of $\vartheta_{p t}$ really do differ along a border, at least one of the times that border county $i$ in state $s$ enters the dataset it would seem to do so without the proper control for the county-specific trend. Indeed, in this situation it seems clear that the error specification in equation (4) cannot be correct. In consequence, one must either be happy with the assumption, in theory, of a model that likely has shared trends at a highly aggregated level or with an estimation procedure in which county-level observations are often entered without consistent controls for geographic trends.

A final approach that has been taken in recent work is the application of synthetic controls to handle the issue of geographically-disparate trends. As stated in Abadie et al. (2010), this model assumes that, for counties in group c:

$$
\lambda_{i s c}(t)=\phi_{t c}+\eta_{i} \mu_{t c} .
$$

This allows the county-specific effects to vary over time (through changes in $\phi$ and $\mu)$ in a potentially non-linear way, but the county-specific component of the change is proportional across all cross-sectional units (that is, $\eta_{i}$ does not vary over time). In this approach, the counties in a particular group include a treated county experiencing a minimum-wage increase along with (potentially several) "control" counties without minimum-wage increases but similar trends in dependent and independent variables in the pre-treatment phase. This allows a treatment effect to be estimated for each treated county examined (with the estimated treatment effects often averaged across the county to report a single estimate). As is typical of matching estimators that explicitly construct counterfactual control groups, the treatment-effect approach provides a lessrestrictive manner of controlling for the effects of other covariates. But our own experience is that estimated minimum-wage elasticities are quite insensitive to the exclusion of other controls in linear models, suggesting these concerns would be less important here. Note also that equation (5) makes clear that this approach is still based on some assumptions about the nature of the evolution of the county-specific trend and, as such, is neither a generalization nor a special case of the alternative approaches allowing for geographic-specific trends discussed here.

\section{The critique of using geographic-specific linear trends}

The most extensive critique of the extension/application of the state panel approach is by Neumark et al. [NSW] $(2013 ; 2014)$. A major part of their criticism has to do with the choice of sample period, raised by other findings from this new phase of research in which significantly negative minimum wage effects do not always vanish with the incorporation of state-specific trends (see Neumark and Wascher 2011). In particular, NSW criticize the analysis of Allegretto et al. (2011), noting that there were recessions at the start (1990-91) and end of their sample period. If recessions do not have an aggregate influence that is common across periods, the longer-term estimated trend could be biased. Specifically Neumark et al. (2014: 616) observe: "This, in turn, could lead to 
misclassification of periods in which teen employment was high or low relative to the predicted values net of the minimum wage and hence influence the estimated minimum wage effect for reasons having nothing to do with the longer-run trends for which the specification is trying to control." By way of illustration, Neumark et al. (2013) present results for California for a model with state-specific trends. The model is estimated initially for the period 1994-2007, thereby excluding the 1990-1991 and 2007-2009 recessions. They plot the actual residuals for this period and then the prediction errors for the two recessionary intervals. It is found that (teenager) employment was much higher than would have been predicted by the model for the first recession but considerably smaller for the second. When the recessionary intervals are included both separately and jointly, the estimates of state-specific trends over the non-recessionary period are strongly influenced by their inclusion.

Given this potential for bias, NSW recommend the use of higher-order trends in panel data models. Alternatively, they also suggest the exclusion of sub-periods of steep recessions in estimating state-level trends while retaining the whole sample to estimate minimum wage effects, or the use of a Hodrick-Prescott filter to detrend the data. They then follow their own advice in estimating a model of teen employment, 19902011(Q2), using CPS data, first with a simple state-specific linear trend and then with a variety of higher-order trends and alternative detrending methods. Apart from the linear trend specifications, they report near universally negative and significant effects of minimum wages on teen employment.

As a practical matter, NSW reserve much of their critique for the border-county approach. We do not feel this is the place to dwell on these comments, other than in the related context of NSW's criticism of the use of Census division/time period interactions in Allegretto et al. (2011). The justification for this latter control, it will be recalled, is again one of spatial heterogeneity: employment rates for low-wage groups vary by Census division, and states within Census divisions serve as better controls for states raising their minimum wages than states in other Census divisions. Concerns about the reduction in identifying variation for estimation, given that states within divisions may not actually be particularly suitable controls, led NSW to consider the use of a synthetic control approach to pick candidate control states. When analyzing impacts of minimum wages on teen employment, NSW argue that synthetic control matching indicates that states outside the Census division actually tend to be better controls for treatment observations, prompting the response from Allegretto et al. (2013) that within-division states are in fact more likely to be chosen by their synthetic control analysis. Much of this disagreement surrounds the appropriate choice of minimumwage-increase events on which to focus the synthetic control approach, the appropriate pre-treatment period to use in these choices, and the choice of variables on which to form the matches (for details, see also Dube and Zipperer 2015). While the syntheticcontrol approach does offer an interesting alternative that allows several case-study events to be analyzed, the disagreements between these two counterparts highlights the fact that there are still many questions about how it might be correctly applied in this case. $^{7}$

This brings us to the second major criticism of the use of state-specific trends, linear or otherwise. In a recent paper, Meer and West (2015) have argued that it is inherently more likely for the effects of minimum wage hikes to be reflected in employment 
dynamics (viz. employment growth) than in employment levels. The theoretical backdrop is a Diamond-type worker search and matching framework in which transitions to a new employment steady state may be slow. ${ }^{8}$ The practical implication is that, if the true effect of policy is to change the slope for an outcome variable rather than its level, the mechanics of the state-specific trend approach can introduce biases in the estimated minimum-wage effects. In particular, any post-treatment deviation in employment growth caused by the treatment will attenuate an estimated static treatment effect if the specification includes a single trend for the pre- and post-treatment periods.

Meer and West estimate several specifications that allow for lagged effects of minimum wages on employment. These models are estimated using three different state panels of administrative employment data: Business Dynamics Statistics (BDS), the QCEW, and the Quarterly Workforce Indicators (QWI). All models also include controls for state population, the share of the population aged 15-59 years, and gross state product per capita, along with a complete set of Census-region/time-period interactions. Some models also allow for state-specific trends in the level of employment. The authors' preferred specification is a so-called break-in-trend model, in which the first difference of employment is regressed on the contemporaneous level of the minimum wage (along with changes in the other controls). For this specification, they report results that are insensitive to the inclusion of state-specific trends, consistent with their argument that state-specific trends in employment-level regressions mask the effects of minimum-wage changes. Across all three datasets, the break-in trend model leads to the inference that total job growth is strongly reduced by increases in the minimum wage. ${ }^{9}$ This result is frankly surprising. The general presumption has been that minimum-wage effects on total employment are so small that there is little need to focus on this measure as an outcome variable, hence the focus of minimum wage studies on low-wage markets such as those for teens and restaurant workers.

\section{Investigation}

Addison et al. (2012) estimated employment and earnings equations for the restaurantand-bar sector using the QCEW for the period 1990-2005. ${ }^{10}$ The sample comprised a balanced panel of 1,825 counties, providing some 116,800 quarterly observations. In what follows, that sample is preserved for the first set of estimations. We also report estimates extending the sample through 2014. We continue to use a balanced sample for the later period, so the number of counties falls to 1,552, although the number of total observations increases to 155,200 .

Our preferred model reflects the addition of restriction (2) to the baseline equation (1) and for county $i$ in state $s$ in quarter $t$, and can be written:

$$
\log \left(E_{i s t}\right)=\beta_{1} \log \left(M W_{s t}\right)+\beta_{2} X_{i s t}+\delta_{i}+\phi_{t}+\gamma_{i} t+\varepsilon_{i t s} .
$$

Assuming geographic-specific trends are absent (or irrelevant) yields the canonical model (with $\gamma_{i}=0$ ).

NSW find that results are sensitive to the use of population weights in estimation ( $A B C$ report a similar finding in specifications without county-specific trends). They find the strongest evidence of disemployment effects when weights are used, and so we continue this practice in our re-estimation. We have also estimated our models with 
average weekly earnings in the restaurant-and-bar sector as the dependent variable; if the identification in the model is defensible, then we would expect to see statisticallysignificant positive effects on weekly earnings. ${ }^{11}$ In fact, in all of our estimations we do find evidence of a positive weekly-earnings impact (see Appendix Tables 5, 6 and 7), and therefore do not dwell on these results in the following discussion.

Employment results for the canonical and county-specific linear trends models are provided in the first and second columns of Table $1 .{ }^{12}$ The canonical model, which does not include country-specific trends, provides a statistically-significant and negative minimum-wage coefficient estimate in the employment equation. Familiarly, following the inclusion of county-specific trends, the coefficient for the minimum wage-although still negative-is now very small and statistically insignificant. Of course, the main purpose of Table 1 is to examine the effect of introducing the same polynomial detrending alternatives as advocated by NSW (and hopefully sidestepping criticism of a specification search by committing to a pre-specified research design suggested by them). Specifically, second-, third-, fourth-, and fifth-order polynomials are considered in the remaining four columns of the table. The use of higher-order trends in two instances serves to render the small estimated minimum wage effect statistically significant. Interestingly, the coefficient estimates for the other regressors are little changed by polynomial detrending with the exception of findings for the unemployment rate variable in the last two columns of the table (the signs of which are now perverse). Overall, however, the results of this first exercise are decidedly mixed and the suggested minimum wage elasticities quite modest.

Table 2 takes up NSW's other suggestions. The first column of the table provides summary results for the minimum wage when the county-specific trend is estimated using only the data for an interval that nets out the recession years at the beginning of the sample period, and then uses these trend estimates to detrend the data for the full sample period. ${ }^{13}$ Use of this revised single trend estimate is inconsequential in our case: the coefficient estimate changes from negative and insignificant to positive and insignificant. The next column of Table 2 is based on a county-specific trend calculation using data between two business cycle peaks (as in NSW, from 1990:3 to 2001:1); these estimates also yield a small positive and statistically insignificant minimum-wage

Table 1 Employment Equations for the Restaurant-and-Bar Sector, 1990-2005, Polynomial Detrending

\begin{tabular}{|c|c|c|c|c|c|c|}
\hline & \multirow[b]{2}{*}{ No trends } & \multicolumn{5}{|c|}{ Order of Polynomial for County-Specific Trends } \\
\hline & & $1^{\text {st }}$ & $2^{\text {nd }}$ & $3^{\text {rd }}$ & $4^{\text {th }}$ & $5^{\text {th }}$ \\
\hline $\begin{array}{l}\text { Log (minimum } \\
\text { wage) }\end{array}$ & $\begin{array}{l}-0.101^{* *} \\
(0.039)\end{array}$ & $\begin{array}{l}-0.006 \\
(0.033)\end{array}$ & $\begin{array}{l}-0.051^{* * *} \\
(0.014)\end{array}$ & $\begin{array}{l}-0.041 \\
(0.027)\end{array}$ & $\begin{array}{l}-0.062^{*} \\
(0.033)\end{array}$ & $\begin{array}{l}-0.046 \\
(0.033)\end{array}$ \\
\hline Log (Average wage) & $\begin{array}{l}-0.139^{* * *} \\
(0.048)\end{array}$ & $\begin{array}{l}-0.129^{* * *} \\
(0.036)\end{array}$ & $\begin{array}{l}-0.116^{* * *} \\
(0.032)\end{array}$ & $\begin{array}{l}-0.097^{* *} \\
(0.038)\end{array}$ & $\begin{array}{l}-0.089^{* *} \\
(0.040)\end{array}$ & $\begin{array}{l}-0.079^{* *} \\
(0.043)\end{array}$ \\
\hline $\begin{array}{l}\text { Log (Total } \\
\text { employment) }\end{array}$ & $\begin{array}{l}0.596^{* * *} \\
(0.053)\end{array}$ & $\begin{array}{l}0.770^{* * *} \\
(0.061)\end{array}$ & $\begin{array}{l}0.776^{* * *} \\
(0.081)\end{array}$ & $\begin{array}{l}0.824^{* * *} \\
(0.097)\end{array}$ & $\begin{array}{l}0.849^{* * *} \\
(0.109)\end{array}$ & $\begin{array}{l}0.869^{* * *} \\
(0.120)\end{array}$ \\
\hline Unemployment Rate & $\begin{array}{l}-0.001 \\
(0.002)\end{array}$ & $\begin{array}{l}0.001 \\
(0.002)\end{array}$ & $\begin{array}{l}0.001 \\
(0.001)\end{array}$ & $\begin{array}{l}0.002 \\
(0.001)\end{array}$ & $\begin{array}{l}0.003^{*} \\
(0.002)\end{array}$ & $\begin{array}{l}0.004^{* *} \\
(0.002)\end{array}$ \\
\hline Log (Population) & $\begin{array}{l}0.327^{* * *} \\
(0.101)\end{array}$ & $\begin{array}{l}0.289^{* * *} \\
(0.066)\end{array}$ & $\begin{array}{l}0.247^{*} \\
(0.136)\end{array}$ & $\begin{array}{l}0.241^{*} \\
(0.133)\end{array}$ & $\begin{array}{l}0.226^{*} \\
(0.125)\end{array}$ & $\begin{array}{l}0.326^{* *} \\
(0.150)\end{array}$ \\
\hline
\end{tabular}

Notes: The dependent variable is the log of employment. The standard errors in parentheses are clustered at the state level. All regressions included fixed-effects for county and quarter. Regressions are weighted by the average population in the respective county. The sample size in all regressions is 116,800 , for a balanced panel of 1,825 counties $* * * * * *, *$ denote statistical significance at the $0.01,0.05$ and 0.10 levels, respectively 
Table 2 Employment Equations for the Restaurant-and-Bar Sector, 1990-2005, Alternative Detrending Methods

\begin{tabular}{llll}
\hline & Post-1993 trends & Peak-to-Peak trends & H-P Filter trends \\
\hline Log (Minimum wage) & $0.001(0.062)$ & $0.027(0.071)$ & $-0.042^{*}(0.023)$ \\
\hline
\end{tabular}

Notes: See Notes to Table 1. All equations include the same controls as in Table 1. Standard errors are block bootstrapped by state using 500 replications. Post-1993 Trends detrends all observations based on county-specific trends estimated over the 1994-2005 period. Peak-to-Peak Trends detrends all data based on county-specific trends estimated over 1990-Q3 to 2001-Q1. H-P Filter Trends are the filtered series from a county-specific application of a Hodrick-Prescott filter (smoothing parameter $=1600$ ) applied individually to each data series

coefficient. Passing each data series by county through a Hodrick-Prescott filter does yield a marginally significant negative coefficient estimate for the minimum wage regressor, but the estimated effect remains small (an elasticity of-0.04). ${ }^{14}$ Once again, however, the earnings counterpart of the lower panel of Table 2 evinces welldetermined coefficient estimates for each of the three alternative detrending methods (see Appendix Table 5).

In the above exercises we use the same interval (1990-2005) as in ABC so as to determine the sensitivity of the (minimum wage) results reported there to alternative representations of county-specific trends suggested by NSW. Next, we extend the QCEW sample period as far as we can-namely, up to 2014-recalling that the period examined by NSW is very similar (1990-2011Q2) albeit for a different sample and dataset (they use teens from the CPS). Table 3 replicates the procedures earlier employed in Tables 1 and 2 using this longer sample. What difference does allowing for a longer sample period make? Perhaps the first observation to be made is that the canonical two-way fixed effects model (with county and time effects) now provides no evidence of minimum wages impacting employment. Interestingly, allowing for county-specific linear trends now leads to a small negative but marginally statistically-significant coefficient estimate. However, use of higher-order county-specific trends fails to yield a single significant minimum wage elasticity. All such coefficients are now less negative than for the linear trend specification, and vis-à-vis their counterparts in Table 1 . It is worth noting that this failure to support minimum-wage effects is not due to an increased imprecision of the estimates induced by the additional trend controls, as the standard errors are actually smaller with the higher-order trend polynomials in three out of four cases. Turning to the lower panel of the table, we see that neither method that uses subperiods of the 1990-2014 period to estimate the county-specific linear

Table 3 Employment Equations for the Restaurant-and-Bar Sector 1990-2014, Various Detrending Methods

\begin{tabular}{|c|c|c|c|c|c|c|}
\hline & \multirow[b]{2}{*}{ No trends } & \multicolumn{5}{|c|}{ Order of Polynomial } \\
\hline & & $1^{\text {st }}$ & $2^{\text {nd }}$ & $3^{\text {rd }}$ & $4^{\text {th }}$ & $5^{\text {th }}$ \\
\hline \multirow[t]{2}{*}{$\begin{array}{l}\text { Log (Minimum } \\
\text { wage) }\end{array}$} & $\begin{array}{l}-0.067 \\
(0.042)\end{array}$ & $\begin{array}{l}-0.043^{*} \\
(0.023)\end{array}$ & $-0.015(0.019)$ & $\begin{array}{l}-0.018 \\
(0.016)\end{array}$ & $-0.027(0.020)$ & $\begin{array}{l}-0.008 \\
(0.015)\end{array}$ \\
\hline & & $\begin{array}{l}\text { Post-1993 } \\
\text { Trends }\end{array}$ & $\begin{array}{l}\text { Peak-to-Peak } \\
\text { Trends }\end{array}$ & $\begin{array}{l}\text { H-P Filter } \\
\text { Trends }\end{array}$ & $\begin{array}{l}\text { Peak-to-Peak, } \\
2000-2015\end{array}$ & \\
\hline $\begin{array}{l}\text { Log (Minimum } \\
\text { wage) }\end{array}$ & & $\begin{array}{l}-0.044 \\
(0.034)\end{array}$ & $0.057(0.115)$ & $\begin{array}{l}-0.014 \\
(0.011)\end{array}$ & $0.073(0.130)$ & \\
\hline
\end{tabular}

Notes: All specifications include the same controls (and approaches to calculating standard errors) as in Tables 1 and 2 . The "Peak-to-Peak, 2000-2015" results use the same period to estimate the linear trends at the county level as in the "peak-to-peak trends" results, but only uses data after this period to then estimate the employment equation using detrended data. The sample size is based on a panel of 1,552 counties. Total observations are 155,200 in all equations except the "Peak-to-Peak, 2000-2015" estimation, where the total observations are 85,360 
trend yields statistically significant results, while deployment of the Hodrick-Prescott filter no longer produces a marginally significant coefficient for the minimum wage.

To this point, the empirical evidence of this investigation has shown that employment effects are relatively small, and, importantly, that there exists substantial sensitivity of estimates with respect to the choice of time period, polynomial trend specification, and trend filter methods. Our own sense is that the most important extension here is the use of higher-order polynomials, as these specifications constitute a generalization of the linear-trend model to one that would allow a time-specific effect for every county. ${ }^{15}$ However, we wanted to take the suggestion of Neumark (2001) that committing to a pre-specified design before approaching the data enhances the believability of one's results, so we have estimated all of the alternative trend specifications suggested in NSW.

We next consider the criticism by Meer and West (2015) of the inclusion of geographic-specific trends, namely that they serve to attenuate the measured effect of the minimum wage on employment. A similar motivation would seem to lie behind Sabia's (2009: 88) argument that state-specific trends in an employment model may "[reduce] potentially important identifying variation." There are several reasons why an empirical researcher might consider omitting a statistically-significant set of geographic-specific trends from a model estimating minimum-wage effects. One is that a significant collinearity problem is induced. This concern is not relevant as far as our results are concerned, as consistent estimates of standard errors for the minimum-wage elasticities are generally not increased by the inclusion of county-specific trends. Another concern is Meer and West's argument that minimum wages may be causing a fall in the trend in employment growth in areas raising the minimum wage, so that controlling for these underlying trends is inappropriate.

Our initial expectation is that this latter concern should not be an issue for the elasticity estimates from the restaurant-and-bar sector. Specifically, $A B C$ report that the downward trends in employment in states raising their minimum wage are actually lessened after minimum-wage increases rather than becoming more strongly negative as Meer and West's argument would imply. For another, we have estimated models using data detrended on the basis of trends estimated for a period prior to the identifying minimum-wage increases. In particular, we used the peak-to-peak period from 1990:3-2000:1 to estimate county-specific linear trends and then adopted these estimated trends to detrend the data from 2000:2-2014:4. Only the latter data were next used to estimate the employment model. By design, the county-specific trends cannot be caused by the subsequent minimum-wage increases. The minimum-wage elasticity estimated in this way is reported in Table 3 as the "peak-to-peak, 2000-2015" estimate, with positive and statistically-insignificant results that are similar to the "peak-to-peak" results estimated from the full data period.

As noted earlier, Meer and West do find a significantly negative minimum wage impact on job growth in models that allow for state-specific trends in the job-growth rate. As Meer and West note, the specification that they seem to prefer-the break-in-trend model-is somewhat hard to defend given its implication that a single minimum-wage increase will have a permanent effect on job growth. Nonetheless, these kinds of specifications - where growth rates are modeled as a function of levels of variables-are not uncommon in economics and, as Meer and West argue, may be useful in picking up 
lagged effects in a parsimonious way (relative to the less restrictive dynamic specifications that they also explore in their paper). ${ }^{16}$ As an attempt to explore the importance of Meer and West's concerns in our data, therefore, we estimated similar models with our 1990-2014 data on restaurants and bars from the QCEW. We preface our discussion of the results presented in Table 4 by noting that Meer and West did use the QCEW in some of their regressions, but their aggregation remained at the state (rather than the county) level, while they also chose to look at the broader-based accommodation and food sector rather than the more low-wage restaurant-and-bar sub-sector. ${ }^{17}$

Our own preference for addressing the concerns raised by Meer and West in a parsimonious fashion is to consider models that explain long-run changes in employment as a function of similar long-run changes in the independent variables. For example, consider a state that raises its minimum wage one time in the panel. An empirical model based on 4-year changes would then have that minimum-wage change showing up as a potential employment change factor for each of the quarters in the corresponding 4year period. With lagged effects we would expect at least some of those quarters in the following 4 years to have reduced employment, leading to a nonzero coefficient on the minimum-wage change variable. Conventional short-run quarterly differenced models would, on the other hand, miss these lagged impacts. The estimated equation is a natural extension of equation (6), as differencing over $p$ periods provides:

$$
\begin{aligned}
\log \left(E_{i s t}\right)-\log \left(E_{i s, t-p}\right)= & \beta_{1}\left[\log \left(M W_{i s t}\right)-\log \left(M W_{i s, t-p}\right)\right]+\beta_{2}\left[X_{i s t}-X_{i s, t-p}\right] \\
& +\left(\phi_{t}-\phi_{t-p}\right)+\gamma_{i} p+\varepsilon_{i s t}^{*} .
\end{aligned}
$$

One advantage of the differenced models is that they also difference out any static geographic-specific effects, while the inclusion of time-period and geographic dummies is equivalent to controlling for geographic-specific linear trends.

$\mathrm{ABC}$ estimated such differenced models but only considered one- and four-quarter differences (in the latter case requiring any lagged effects to manifest themselves within a year). Here, we consider the robustness of this finding to expanding the sample period to 2014, and considering even longer differences to allow for more significant lagged effects. The first column of Table 4 presents results for the break-in-trend model in which the minimum wage is expressed in levels. In the second column of the table, all variables are differenced over one quarter and the model again estimated for the entire sample period. ${ }^{18}$ Next, as the longest difference we consider is 6 years, we maintain a consistent sample across the four additional specifications given in the remaining columns of the table by starting our estimation with observations beginning in 1996 rather than 1990. That is, the last four columns of Table 4 report estimates from fully-

\begin{tabular}{|c|c|c|c|c|c|c|}
\hline \multirow{2}{*}{$\begin{array}{l}\text { Time period } \\
\text { Difference length }\end{array}$} & \multicolumn{2}{|l|}{ 1990-2014 } & \multicolumn{4}{|l|}{ 1996-2014 } \\
\hline & 1 quarter & 1 quarter & 1 quarter & 1 year & 4 years & 6 years \\
\hline Log (Minimum wage) & $0.004(0.003)$ & $-0.002(0.019)$ & $0.005(0.020)$ & $0.001(0.009)$ & $-0.011(0.022)$ & $-0.007(0.031)$ \\
\hline Specification of MW & Levels & Differenced & Differenced & Differenced & Differenced & Differenced \\
\hline
\end{tabular}

Table 4 Differenced Employment Equations for the Restaurant-and-Bar Sector, 1990/1996-2014

Notes: See Notes to Table 1. All specifications include the change in the local unemployment rate and log county population as controls, along with region/quarter fixed effects and county fixed effects. In the "levels" equation, the dependent variable is first-differenced, but the minimum wage variable is measured in levels. In the differenced equations, all variables are differenced over the same stated period. Sample size is 153,648 in the first two columns, and 117,952 in the other columns 
differenced equations with differences measured over $1,4,16$, and 24 quarters. As is evident in all of these cases, the estimated minimum-wage elasticities are small and statistically insignificant. The bottom line in our focus of study, then, is that possible minimum-wage effects of employment growth in the restaurant-and-bar sector do not seem to be of concern.

Finally, we note that Dube (2013) has also directly questioned results from Meer and West's break-in-trend equation. Using the BDS and QCEW, he broadly replicates the Meer-West result on aggregate, although upon disaggregation with the QCEW no effect is found for the accommodation-and-food-services sector. This would seem to be at odds with the results of Meer and West (2013), who in earlier reporting negative and statistically significant effects for that sector pointed to differences in time periods and (business cycle) controls as likely being the culprit. ${ }^{19}$

\section{Conclusions}

The debate on the impact of minimum wages is ongoing. An important recent focus has centered on the proper manner in which to incorporate trends in employment outcomes that may differ across geographic areas where minimum wages follow different paths over time. Attempts to address these concerns have led to several approaches that allow employment to evolve independently (to some degree) across regions/divisions, border-county pairs, or states not among those selected as a synthetic control for a particular treated state. All these approaches require some assumptions, however, about a lack of independence in trends within some subset of geographic areas. A primary alternative approach has been to model economic outcomes in ways that allow them to trend in a completely independent fashion across geographic areas, although with a parametric assumption (linear) about the nature of these geographic-specific trends. In this paper, we continue to follow this independent-trends approach, though by relaxing many of the assumptions that underlie the strict parametric nature of estimated trends in the earliest research that used this approach. We also evaluate the criticisms of Meer and West-to the effect that the research focus should shift to employment growth in estimating minimum-wage outcomes-using our restaurantand-bar sector data.

Criticism in the minimum-wage literature can of course be constructive. A pertinent example is the suggestion that an environment of deep recession might well produce clearer evidence of disemployment than has been reported in much of the modern minimum wage literature. Addison et al. (2013) focused on two high-risk groups over the years 2005-2010, and while the evidence for a general disemployment effect was not uniform, their estimates did suggest the presence of negative minimum wage effects for teens in states hardest hit by the recession.

In the present treatment, we have evaluated the sensitivity of results from restaurants and bars to the generalizations of the parametric modeling of county-specific trends, and our results do not serve to dislodge the persistent finding of considerably low (and possibly zero) minimum-wage elasticities in that sector. We also fail to find any suggestion that the use of data detrended at the county level leads to inconsistent estimation of minimum-wage effects in the restaurant-and-bar sector because of concerns pointed to by Meer and West (2015). Indeed, estimation of the minimum-wage effect over the longest period we now have available with the 
QCEW (from 1990 to 2014) leads to insignificant effects even ignoring possible geographic-specific trends. Overall, the empirical evidence suggests that minimum wage employment effects in this sector are quite small and generally insensitive to the inclusion and specification of trends, as well as choice of time period.

While employment effects of minimum wages tend to garner the lion's share of the focus in this literature, it may be better that increased attention be paid to concerns having to do with the effects of minimum wages on other outcomes: hours, non-wage benefits, training, as well as other margins of adjustment (prices, profits, turnover, and performance standards) as suggested by Hirsch et al. (2015). And although we did not on this occasion find any great support for the argument that geographic-specific time trends serve to attenuate the measured effects on employment levels, the notion that minimum wages might have an effect on the nature of employment dynamics (including firm births) has recently become an area of an increasing focus in this literature (Portugal and Cardoso (2006); Gittings and Schmutte (2015), Dube, Lester, and Reich (2014).

\section{Endnotes}

${ }^{1}$ The vast majority of the studies summarized employed a panel-data approach, with varying assumptions about geographic-specific linear trends. See also an earlier metaanalysis by Doucouliagos and Stanley (2009) that suggests, after having taken publication bias into account, a not dissimilar conclusion in arriving at a minimum-wage elasticity of -0.01 .

${ }^{2}$ Similar results for employment are reported by Dube et al. (2010: Table 2) using the Quarterly Census of Employment and Wages.

${ }^{3} \mathrm{ABC}$ also reported a similar pattern when state-level trends were substituted for county-level trends.

${ }^{4}$ A similar finding for teenagers using the Quarterly Workforce Indicators dataset is reported in Dube et al. (2012).

${ }^{5}$ In fact, Allegretto, Dube and Reich estimate their models at the state level. In some specifications they combine (2) and (3), with state-specific rather than county-specific trends.

${ }^{6}$ This requires the same county being entered into the estimation sample multiple times, with a different border-pair effect estimated each time.

${ }^{7}$ For example, there is still the issue of how to draw clear statistical inferences from estimates using synthetic controls. There is also the assumption-made clear in equation (5) - that all cross-sectional units follow the same proportional trend after the treatment. This assumption is at odds with the findings of NSW that there may be important geographic differences in nonlinear trends that are correlated with minimumwage changes.

${ }^{8}$ Ironically, the Meer-West model rests on a similar search-theoretic reasoning to that employed by protagonists of the argument that minimum wages will not adversely impact employment because of improved matching in the labor market, although they themselves accept that negative effects will win out because of a differentially reduced rate of job growth.

${ }^{9}$ Their BDS results suggest that a 10 percent increase in the minimum wage nationwide would lead to a reduction in the employment growth rate-both currently and in 
the future, as long as the minimum wage was kept at the same real value-by 0.2 percentage points. That amounts to an immediate loss of roughly 600,000 jobs (at current employment levels) and a similar-sized additional job loss every year in the future.

${ }^{10} \mathrm{We}$ refer readers to the earlier study for details on variable definitions from the QCEW and other data sources.

${ }^{11}$ Admittedly, this expectation assumes that weekly hours are not reduced by a larger magnitude than hourly earnings are increased, but previous analysis of hours effects does not suggest evidence of such large effects (see Belman and Wolfson 2014).

${ }^{12}$ These results differ very slightly from those reported in $\mathrm{ABC}$, as we now follow the recent literature in excluding the enrollment rate as a control, the inclusion of which has been criticized on the grounds that it may itself be a function of the minimum wage.

${ }^{13}$ We also follow NSW in using a block bootstrap at the state level for calculating standard errors for the non-standard detrending approaches in Table 2.

${ }^{14} \mathrm{We}$ are personally less convinced by results using the H-P filter compared with the other detrending methods. This is partly due to a general lack of experience in its use in labor economics research (also noted by Allegretto et al. 2013). We also note that the filter has been criticized as overly mechanical by those more experienced with its use, with the filter tending to find cycles in data even when such cycles are not present (see, for example, Cogley and Nason 1995).

${ }^{15}$ This is similar to the argument that higher-order polynomials be used to approximate unknown functional forms in regression-discontinuity designs (see Angrist and Pischke 2009, pp. 253-255).

${ }^{16}$ Simple lag structures have been incorporated in several studies in the recent minimum-wage literature (e.g., via inclusion of a simple lagged minimum wage as an additional control). Our sense is that these embellishments are generally inconsequential as regards the conclusions reached.

${ }^{17}$ The estimated equation is basically equation (6) with the change in the log employment from the prior period (rather than the level of log employment) as the dependent variable, and the change in the $\mathrm{X}$ vector as the set of controls. As Meer and West argue that minimum wage effects may affect total employment, we drop that latter variable as a control (along with the measure of average weekly earnings across all sectors). The only other modification is the inclusion of region/quarter fixed effects as additional controls, as in the equations estimated by Meer and West.

${ }^{18}$ Both the level and first difference of the log minimum wage can be included in the same job-growth model estimation. When we do so, both are statistically insignificant. On the other hand, if we include both in an earnings-change equation, only the coefficient for the change in the minimum-wage is found to be statistically significant. The latter result does suggest the first-difference specification is more relevant than the break-in-trend specification.

${ }^{19}$ On the other hand, our failure to find effects in the more targeted restaurantand-bar sector-using quarterly data with a local-economy control (like Meer and West)-raises doubts similar to those of Dube regarding the relevance of the break-in-trend model. 


\section{Appendix}

Table 5 Earnings Elasticities for the Restaurant-and-Bar Sector 1990-2005, Various Detrending Methods

\begin{tabular}{|c|c|c|c|c|c|c|}
\hline & \multirow[b]{2}{*}{ No trends } & \multicolumn{5}{|c|}{ Order of Polynomial } \\
\hline & & $1^{\text {st }}$ & $2^{\text {nd }}$ & $3^{\text {rd }}$ & $4^{\text {th }}$ & $5^{\text {th }}$ \\
\hline \multirow[t]{2}{*}{$\begin{array}{l}\text { Log (Minimum } \\
\text { wage) }\end{array}$} & $\begin{array}{l}0.199 * * * \\
(0.021)\end{array}$ & $\begin{array}{l}0.171^{* * *} \\
(0.036)\end{array}$ & $0.141^{* * *}(0.023)$ & $\begin{array}{l}0.093^{* * *} \\
(0.027)\end{array}$ & $\begin{array}{l}0.099^{* * * *} \\
(0.032)\end{array}$ & $\begin{array}{l}0.079 * * \\
(0.034)\end{array}$ \\
\hline & & $\begin{array}{l}\text { Post-1993 } \\
\text { Trends }\end{array}$ & $\begin{array}{l}\text { Peak-to-Peak } \\
\text { Trends }\end{array}$ & $\begin{array}{l}\text { H-P Filter } \\
\text { Trends }\end{array}$ & & \\
\hline $\begin{array}{l}\text { Log (Minimum } \\
\text { wage) }\end{array}$ & & $\begin{array}{l}0.198^{* * *} \\
(0.055)\end{array}$ & $0.229 * * *(0.053)$ & $\begin{array}{l}0.096^{* *} \\
(0.030)\end{array}$ & & \\
\hline
\end{tabular}

Notes: The dependent variable in all models is the average weekly earnings of workers in the restaurant-and-bar sector. See Notes to Tables 1 and 2 for other details

Table 6 Earnings Elasticities for the Restaurant-and-Bar Sector 1990-2014, Various Detrending Methods

\begin{tabular}{|c|c|c|c|c|c|c|}
\hline & \multirow[b]{2}{*}{ No trends } & \multicolumn{5}{|c|}{ Order of Polynomial } \\
\hline & & $\overline{1^{\text {st }}}$ & $2^{\text {nd }}$ & $3^{\text {rd }}$ & $4^{\text {th }}$ & $5^{\text {th }}$ \\
\hline \multirow[t]{2}{*}{$\begin{array}{l}\text { Log (Minimum } \\
\text { wage) }\end{array}$} & $\begin{array}{l}0.222^{* * *} \\
(0.022)\end{array}$ & $\begin{array}{l}0.171^{* * *} \\
(0.021)\end{array}$ & $0.170^{* * *}(0.021)$ & $\begin{array}{l}0.150^{* * *} \\
(0.013)\end{array}$ & $0.152^{* * *}(0.012)$ & $\begin{array}{l}0.131^{* *} \\
(0.016)\end{array}$ \\
\hline & & $\begin{array}{l}\text { Post-1993 } \\
\text { Trends }\end{array}$ & $\begin{array}{l}\text { Peak-to-Peak } \\
\text { Trends }\end{array}$ & $\begin{array}{l}\text { H-P Filter } \\
\text { Trends }\end{array}$ & $\begin{array}{l}\text { Peak-to-Peak, } \\
\text { 2000-2015 }\end{array}$ & \\
\hline $\begin{array}{l}\text { Log (Minimum } \\
\text { wage) }\end{array}$ & & $\begin{array}{l}0.166^{* * *} \\
(0.022)\end{array}$ & $0.146^{* * *}(0.052)$ & $\begin{array}{l}0.125^{* *} \\
(0.014)\end{array}$ & $0.148^{* *}(0.064)$ & \\
\hline
\end{tabular}

Notes: The dependent variable in all models is the average weekly earnings of workers in the restaurant-and-bar sector. See Notes to Table 3 for other details

Table 7 Differenced Earnings Equations for the Restaurant-and-Bar Sector, 1990/1996-2014

\begin{tabular}{|c|c|c|c|c|c|c|}
\hline Time Period & 1990-2014 & & 1996-2014 & & & \\
\hline $\begin{array}{l}\text { Difference } \\
\text { Length }\end{array}$ & 1 quarter & 1 quarter & 1 quarter & 1 year & 4 years & 6 years \\
\hline $\begin{array}{l}\text { Log (Minimum } \\
\text { wage) }\end{array}$ & $\begin{array}{l}0.010^{* * *} \\
(0.002)\end{array}$ & $\begin{array}{l}0.101^{* * *} \\
(0.026)\end{array}$ & $\begin{array}{l}0.108^{* * *} \\
(0.029)\end{array}$ & $\begin{array}{l}0.131^{* * *} \\
(0.010)\end{array}$ & $\begin{array}{l}0.185^{* * *} \\
(0.019)\end{array}$ & $\begin{array}{l}0.203^{* * *} \\
(0.026)\end{array}$ \\
\hline $\begin{array}{l}\text { Specification } \\
\text { of } M W\end{array}$ & Levels & Differenced & Differenced & Differenced & Differenced & Differenced \\
\hline
\end{tabular}

Notes: The dependent variable is the change in the log of average weekly earnings in the restaurant-and-bar sector (differenced at the specified length). See Notes to Table 4 for other details 


\section{Abbreviations}

ABC: Addison, Blackburn, Cotti (2012); BDS: Business Dynamics Statistics; CPS: Current Populations Survey; NSW: Neumark, Salas, Wascher (2013, 2014); QCEW: Quarterly Census of Employment and Wages; QWI: Quarterly Workforce Indicators.

\section{Competing interests}

The IZA Journal of Labor Economics is committed to the IZA Guiding Principles of Research Integrity. The authors declare that they have observed these principles.

\section{Acknowledgement}

This paper was presented at the workshop on Minimum Wages in China, Hong Kong and the World at The Hong Kong University of Science and Technology, at the IWH/Halle Institute for Economic Research Seminar in Economics, and at the IAB International Workshop on the German Minimum Wage - First Evidence and Experiences from Other Countries. The authors thank without implicating participants for their helpful remarks.

Responsible editor: Pierre Cahuc.

\section{Author details}

${ }^{1}$ University of South Carolina, Columbia, SC, USA. ${ }^{2}$ Durham University, Durham, UK. ${ }^{3}$ IZA, Bonn, Germany. ${ }^{4}$ University of Wisconsin-Oshkosh, Oshkosh, WI, USA.

Received: 10 August 2015 Accepted: 23 November 2015

Published online: 29 December 2015

\section{References}

Abadie A, Diamond A, Hainmueller J (2010) Synthetic control methods for comparative case studies: estimating the effect of California's tobacco control program. J Am Stat Assoc 105(490):493-505

Addison JT, Blackburn MKL, Cotti CD (2009) Do minimum wages raise employment? evidence from the u.s. retail-trade sector. Labour Econ 16(4):397-408

Addison JT, Blackburn ML, Cotti CD (2012) The effect of minimum wages on labour market outcomes: county-level estimates from the restaurant-and-bar sector. Br J Ind Relat 50(3):412-435

Addison JT, Blackburn MKL, Cotti CD (2013) Minimum wage increases in a recessionary environment. Labour Econ 23:30-39

Allegretto SA, Dube A, Reich M (2011) Do minimum wages really reduce teen employment? Accounting for heterogeneity and selectivity in state panel data. Ind Relat 50(2):205-240

Allegretto SA, Dube A, Reich M, Zipperer B (2013) Credible research designs for minimum wage studies, IZA Discussion Paper No. 7638. Institute for the Study of Labor, Bonn

Angrist JD, Pischke J-S (2009) Mostly harmless econometrics: an empiricist's companion. Princeton University Press, Princeton, NJ Belman D, Wolfson P (2014) What does the minimum wage do? W.E. Upjohn Institute for Employment Research, Kalamazoo, MI

Cogley T, Nason JM (1995) Effects of the Hodrick-Prescott filter on trend and difference stationary time series: implications for business cycle research. J Econ Dyn Control 19(1):253-278

Doucouliagos H, Stanley TD (2009) Publication selection bias in minimum wage research? A meta-regression analysis. Br J Ind Relat 47(2):406-428

Dube A (2013) Minimum wages and aggregate job growth: causal effect or statistical artifact? IZA Discussion Paper No. 7674. Institute for the Study of Labor, Bonn

Dube A, Zipperer B (2015) Pooled synthetic control estimates for recurring treatments: an application to minimum wage case studies, IZA Discussion Paper No. 8944. Institute for the Study of Labor, Bonn

Dube A, Lester TW, Reich M (2010) Minimum wage effects across state borders: estimates using contiguous counties. Rev Econ Stat 92(4):945-964

Dube A, Lester TW, Reich M (2012) Minimum wage shocks, employment flows, and labor market frictions". mimeographed. Institute for Research on Labor and Employment, Berkeley

Dube A, Lester TW, Reich M (2014) Minimum wage shocks, employment flows and labor market frictions. Institute for Research on Labor and Employment Working Paper. 149-13.

Gittings RK, Schmutte IM (2015) Getting handcuffs on an octopus: minimum wages, employment, and turnover., Available at http://people.terry.uga.edu/schmutte/content/GittingsSchmutte_MinWage_2015Feb06.pdf

Hirsch BT, Kaufman BE, Zelenska T (2015) Minimum wage channels of adjustment. Ind Relat 54(2):199-239

Meer J, West J (2013) Supplemental appendix for effects of the minimum wage on employment dynamics., Available at http://web.mit.edu/westj/www/articles/Meer_West_MinimumWage_Appendix_2013.pdf

Meer J, West J (2015) Effects of the Minimum Wage on Employment Dynamics, Previous version published as NBER Working Paper 19262. National Bureau of Economic Research, 2013, Cambridge

Neumark D (2001) The employment effects of minimum wages: evidence from a prespecified research design. Ind Relat 40(1):121-144

Neumark D, Wascher W (2007) Minimum wages and employment. Foundations in Microeconomics 3(1):1-182

Neumark D, Wascher W (2008) Minimum wages. Cambridge University Press, Cambridge, MA

Neumark D, Wascher W (2011) Does a higher minimum wage enhance the effectiveness of the earned income tax credit? Ind Labor Relat Rev 64(4):712-746

Neumark D, lan Salas JM, Wascher W (2013) Revisiting the minimum wage and employment debate: throwing out the baby with the bathwater? NBER Working Paper No. 18681. National Bureau of Economic Research, Cambridge

Neumark D, lan Salas JM, Wascher W (2014) Revisiting the minimum wage and employment debate: throwing out the baby with the bathwater? Ind Labor Relat Rev 67(Supplement):608-648

Portugal P, Cardoso AR (2006) Disentangling the minimum wage puzzle: an analysis of worker accessions and separations. J Eur Econ Assoc 4(5):988-1013

Sabia JJ (2009) The effects of minimum wage increases on retail employment and hours: new evidence from monthly CPS data. J Lab Res 30(1):75-97 